\title{
Addition of Vancomycin to Cefazolin Prophylaxis Is Associated With Acute Kidney Injury After Primary Joint Arthroplasty
}

\author{
P. Maxwell Courtney MD, Christopher M. Melnic MD, \\ Zachary Zimmer MD, Jason Anari MD, \\ Gwo-Chin Lee MD
}

Published online: 25 November 2014

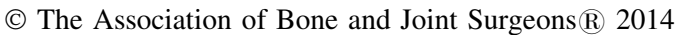

\begin{abstract}
Background With increasing prevalence of methicillinresistant Staphylococcus aureus (MRSA) in patients undergoing hip and knee arthroplasty, some have advocated a dual-antibiotic regimen including vancomycin as prophylaxis against surgical site infections. However, routine administration of vancomycin may result in impaired renal functions in susceptible patients.

Questions/purposes The purpose of this study was to determine whether patients receiving antibiotic prophylaxis with cefazolin and vancomycin have a higher risk of postoperative acute kidney injury (AKI) compared with patients receiving cefazolin alone before elective primary hip and knee arthroplasty. We also aimed to compare
\end{abstract}

Each author certifies that he or she, or a member of his or her immediate family, has no funding or commercial associations (eg, consultancies, stock ownership, equity interest, patent/licensing arrangements, etc) that might pose a conflict of interest in connection with the submitted article.

All ICMJE Conflict of Interest Forms for authors and Clinical Orthopaedics and Related Research ${ }^{\circledR}$ editors and board members are on file with the publication and can be viewed on request.

Each author certifies that his or her institution approved the human protocol for this investigation, that all investigations were conducted in conformity with ethical principles of research, and that informed consent for participation in the study was obtained.

P. M. Courtney, C. M. Melnic, Z. Zimmer, J. Anari, G.-C. Lee Department of Orthopaedic Surgery, Penn Presbyterian Medical Center, University of Pennsylvania, Philadelphia, PA, USA

P. M. Courtney, C. M. Melnic, Z. Zimmer,

J. Anari, G.-C. Lee $(\square)$

Department of Orthopaedic Surgery, Hospital of the University of Pennsylvania, 3400 Spruce Street, 2 Silverstein, Philadelphia, PA 19104, USA

e-mail: gwo-chin.lee@uphs.upenn.edu severity and recovery of AKI in these two cohorts and to determine independent risk factors for AKI.

Methods We retrospectively evaluated a series of 1828 patients undergoing primary hip and knee arthroplasty over a 2-year period who received either cefazolin $(\mathrm{n}=500)$ or cefazolin and vancomycin $(n=1328)$ as perioperative antibiotic prophylaxis. During the study period, a perceived high prevalence of MRSA infections at our institution led some surgeons to add vancomycin to the prophylactic antibiotic regimen. The patient characteristics, case mix, and preoperative renal function and baseline creatinine clearance were similar between the two groups. We defined AKI according to the published Acute Kidney Injury Network (AKIN) criteria, and the risk of AKI in both groups was compared. We also compared the proportions of patients by AKIN severity stage and assessed recovery as defined by creatinine levels showing kidney function reaching 50\% baseline. The American Society of Anesthesiologists (ASA) classification, preoperative chronic kidney disease, intraoperative fluid requirements, and estimated blood loss were recorded. We analyzed the data using a multivariate logistic regression model to identify potential independent risk factors, including dual antibiotic therapy.

Results Patients receiving dual antibiotics were more likely to develop AKI compared with those receiving cefazolin alone ( $13 \%$ versus $8 \%, p=0.002)$. Dual-antibiotic prophylaxis also was associated with greater severity; patients in the dual antibiotic group had higher rates of Grade II and III acute kidney injury (3\% versus $0 \%$, $\mathrm{p}=0.003$ ). There was no difference in the rate of return to baseline renal function $(2 \pm 1.4$ days versus $3 \pm 3.4$ days; mean difference, 0.5 days; $95 \%$ confidence interval [CI], -0.2 to 1.2 days; $p=0.155$ ). Controlling for confounding variables, dual antibiotic prophylaxis (adjusted odds ratio $[\mathrm{OR}], 1.82 ; 95 \% \mathrm{CI}, 1.25-2.64 ; \mathrm{p}=0.002)$, ASA class 
(adjusted OR, 1.64; 95\% CI, 1.24-2.17; $\mathrm{p}=0.001$ ), and preoperative kidney disease (adjusted OR, 1.81; 95\% CI, $1.30-2.52 ; \mathrm{p}=0.001$ ) were independent risk factors for AKI after primary total joint arthroplasty.

Conclusions Without a clear advantage in reducing surgical site infections, the utility and safety of routine addition of vancomycin to the prophylactic regimen in all patients undergoing primary hip and knee arthroplasty should be avoided. Further prospective studies should look at the efficacy of preoperative MRSA screening, decolonization, and selective use of vancomycin in high-risk patients.

Level of Evidence Level III, therapeutic study.

\section{Introduction}

Surgical site infections (SSIs) are a considerable burden to patients, surgeons, and the healthcare system accounting for nearly $25 \%$ of all nosocomial infections per year in the United States [15, 21]. Among patients undergoing primary THA and TKA, infection is a devastating complication resulting in increased costs, length of stay, and patient morbidity $[5,12,23,26,32]$. Today, an estimated $15 \%$ of all revision hip and $25 \%$ of revision knee arthroplasties are performed for infections [6, 7]. Several clinical, surgical, and environmental strategies have been shown to decrease infection rates after primary total joint arthroplasty (TJA) including the use of antibiotic-impregnated cement, decreasing traffic in the operating room, use of ultraviolet light, and, in some instances, use of laminar flow [3, 19, 22, 25, 27]. However, routine administration of prophylactic antibiotic 1 hour before surgical incision has been shown to be the most effective in decreasing the risk of SSI in primary TJA [9, 16, 28, 29]. The American Academy of Orthopaedic Surgeons currently recommends the use of either cefazolin or cefuroxime in patients undergoing any orthopaedic procedure [1]. With increasing prevalence of methicillin-resistant Staphylococcus aureus (MRSA) in patients undergoing hip and knee arthroplasty (THA and TKA), some authors have suggested the addition to vancomycin to the prophylactic antibiotic regimen [2, 8, 37].

Routine administration of vancomycin can have several drawbacks. Although vancomycin has proven pharmacologic efficacy against MRSA, it has no activity against gramnegative aerobes or anaerobes and must be used in combination with traditional prophylactic agents to provide complete coverage [11]. Additionally, the effectiveness and superiority of the addition of vancomycin to the standard prophylactic regimen in infection prevention continues to be debated [33, $36,37,39]$. Finally, exposure to vancomycin has been shown to be a risk factor for the development of resistant organisms, hearing loss, and acute kidney injury (AKI) [2, 13, 14, 40].
Therefore, the purposes of this study are to (1) compare risk of developing AKI between patients receiving prophylactic cefazolin with versus without the addition of vancomycin; (2) compare the severity and recovery of AKI in these cohorts; and (3) determine the independent risk factors for AKI in patients undergoing primary hip and knee arthroplasty.

\section{Materials and Methods}

We identified 2215 patients who underwent primary THA and TKA between September 2008 and December 2010. We excluded 325 patients with a documented drug allergy to penicillin, cephalosporins, or vancomycin and another 62 patients who received a different antibiotic prophylaxis other than cefazolin only or cefazolin and vancomycin. This left 1828 patients for analysis (Fig. 1). Weight-based doses of cefazolin alone $(1 \mathrm{~g}$ if less than $80 \mathrm{~kg}$ in weight or 2 gif greater than $80 \mathrm{~kg}$ ) or cefazolin and vancomycin $(15 \mathrm{mg} / \mathrm{kg})$ were concurrently given and completed within 60 minutes before surgical incision and discontinued after 24 hours postoperatively. All surgeries were performed by one of four fellowship-trained arthroplasty surgeons (CLI, CLN, JPG, G-CL) at one institution. Antibiotic-impregnated cement was not routinely used for primary THA/ TKA during the study period. The rate of SSI in this series of patients was shown to be similar between the two groups and previously published $[17,36]$. The study was approved and conducted according to the guidelines set forth by our institutional review board.

Our institutional Infection Control Committee had recommended the addition of vancomycin to the antibiotic prophylaxis regimen based on the high prevalence of MRSA infections treated at this institution and on their successful reduction of SSIs in patients undergoing cardiac surgery. Patients were not prescreened for MRSA colonization before surgery. The decision to proceed with dual antibiotic prophylaxis was left to the discretion of the operating surgeon. Three of the four surgeons universally adopted the recommendation for all their patients with a single surgeon (G-CL) abstaining.

We recorded patient variables that could impact postoperative renal function, including the American Society of Anesthesiologists (ASA) classification, age, surgical procedure, estimated blood loss (EBL), intraoperative fluid requirements, and preoperative kidney function. For each patient, the pre- and postoperative creatinine was documented, and the individual glomerular filtration rate (GFR) was calculated [24]. All patients had preoperative and at least one postoperative creatinine documented in the medical record. A patient was classified as having preoperative kidney disease if the preoperative GFR was less than $60 \mathrm{~mL} /$ $\mathrm{min} / 1.73 \mathrm{~m}^{2}$ within 30 days before surgery [31]. We defined and classified postoperative AKI according to the published 


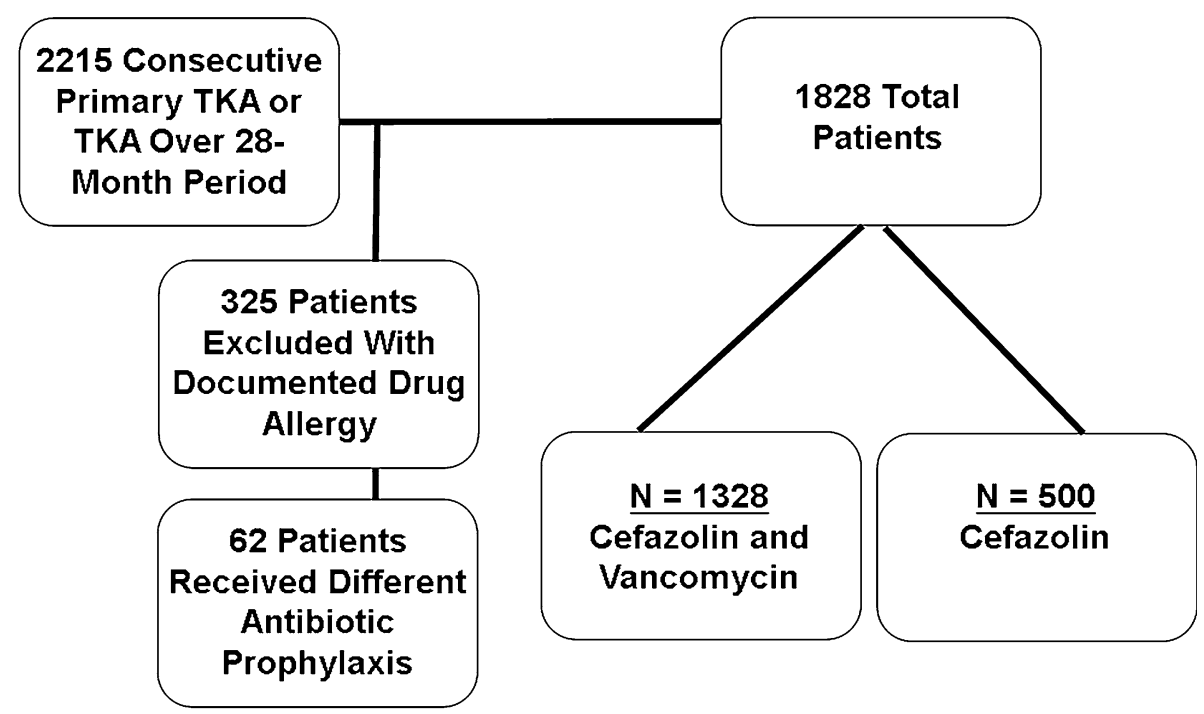

Fig. 1 Schematic diagram demonstrating patient selection in the study.

Table 1. Acute Kidney Injury Network definition and classification of kidney dysfunction

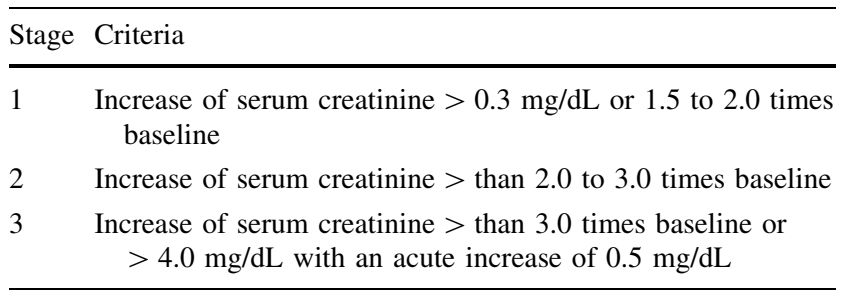

Acute Kidney Injury Network (AKIN) criteria (Table 1) [31]. For patients who developed postoperative AKI, we continued to trend creatinine values and noted days to return to $50 \%$ of baseline kidney function.

Overall, the cefazolin group and cefazolin and vancomycin group were similar and comparable. There were no differences between the two groups in terms of procedure type (THA/TKA) and ASA class (Table 2). Additionally, the dual antibiotic group and the cefazolin only group were similar with respect to mean EBL, intraoperative fluid requirements, prevalence of preoperative kidney disease, preoperative creatinine, and GFR (Table 3).

\section{Statistical Analysis}

We first performed an a priori power analysis to identify an adequately powered sample size for this study. Our primary outcome was to determine if there was a significant difference in the rates of AKI between the two antibiotic groups. To detect a small effect size of $w=0.10$ with a Type I error rate of 0.05 and power of 0.90 , it was determined that a minimum of 1051 patients would be required
Table 2. Demographics of patients by perioperative antibiotic group

\begin{tabular}{llll}
\hline Demographic data & $\begin{array}{l}\text { Ancef only } \\
(\mathrm{n}=500)\end{array}$ & $\begin{array}{l}\text { Ancef + vancomycin } \\
(\mathrm{n}=1328)\end{array}$ & $\mathrm{p}$ value \\
\hline $\begin{array}{l}\text { Mean age (years) (SD) } \\
\text { Sex (\%) }\end{array}$ & & & \\
$\quad$ Male & $222(12.0)$ & $60.6(12.5)$ & 0.123 \\
Female & $278(56)$ & $849(64)$ & 0.001 \\
ASA class (\%) & & & \\
1 or 2 & $275(56)$ & $747(56)$ & 0.631 \\
3 or 4 & $225(44)$ & $581(44)$ & \\
Arthroplasty site (\%) & & & 0.268 \\
Knee & $311(62)$ & $863(65)$ & \\
Hip & $189(38)$ & $465(35)$ & \\
\hline
\end{tabular}

ASA $=$ American Society of Anesthesiologists.

Table 3. Comparison of outcomes between patients receiving cefazolin alone and cefazolin plus vancomycin perioperatively

\begin{tabular}{|c|c|c|c|}
\hline $\begin{array}{l}\text { Patient } \\
\text { variable }\end{array}$ & $\begin{array}{l}\text { Ancef only } \\
(\mathrm{n}=500)\end{array}$ & $\begin{array}{l}\text { Ancef }+ \text { vancomycin } \\
(\mathrm{n}=1328)\end{array}$ & $\begin{array}{l}\mathrm{p} \\
\text { value }\end{array}$ \\
\hline $\begin{array}{l}\text { Estimated blood loss } \\
\quad(\mathrm{mL})(\mathrm{SD})\end{array}$ & 277 (418) & 223 (309) & 0.476 \\
\hline $\begin{array}{l}\text { Intraoperative fluids } \\
\quad(\mathrm{mL})(\mathrm{SD})\end{array}$ & $1825(890)$ & 1837 (874) & 0.576 \\
\hline $\begin{array}{l}\text { Preoperative kidney } \\
\text { disease }(\%)\end{array}$ & $128(26)$ & $283(21)$ & 0.050 \\
\hline $\begin{array}{l}\text { Preoperative GFR (mL/ } \\
\left.\mathrm{min} / 1.73 \mathrm{~m}^{2}\right)(\mathrm{SD})\end{array}$ & $77.0(26)$ & $78.6(26)$ & 0.645 \\
\hline $\begin{array}{l}\text { Preoperative creatinine } \\
(\mathrm{mg} / \mathrm{dL})(\mathrm{SD})\end{array}$ & $1.00(0.84)$ & $0.92(0.54)$ & 0.844 \\
\hline
\end{tabular}

$\mathrm{GFR}=$ glomerular filtration rate 
for this study. Categorical variables between the cefazolin group and cefazolin and vancomycin groups were compared using the Pearson's chi-square test. When any observed or expected value was less than 5, the Fisher's exact test was used. The level of statistical significance was set at $\mathrm{p}<0.05$. Univariate logistic regression analysis of all variables to identify risk factors for postoperative AKI was performed. To control for potentially confounding variables, the data were also analyzed using a multivariate logistic regression model to identify independent risk factors for AKI after primary THA/TKA.

\section{Results}

Patients in the dual antibiotic group (cefazolin and vancomycin) were more likely to develop AKI after surgery compared with patients who received cefazolin alone $(13 \%$ [168 of 1328] versus 8\% [39 of 500], adjusted odds ratio [OR], 1.82; 95\% confidence interval [CI], 1.25-2.64; $\mathrm{p}=0.002$ ) (Table 4). Overall, the risk of AKI after surgery was $11 \%$ (207 patients).

Patients who received vancomycin and cefazolin were more likely to develop more severe renal dysfunction postoperatively compared with patients receiving cefazolin alone. Although most patients with renal dysfunction were classified as Stage I, patients receiving dual antibiotic prophylaxis were more likely to have severe Grades II and III kidney injuries (3\% [41 of 168] versus $0 \%$ [zero of 39], $\mathrm{p}<0.001$ ) (Table 5). Of the 207 patients who developed AKI postoperatively, these

Table 4. Rates of acute kidney injury and surgical site infection separated by choice of antibiotic prophylaxis

\begin{tabular}{lclc}
\hline Study outcome & $\begin{array}{l}\text { Ancef only } \\
(\mathrm{n}=500)\end{array}$ & $\begin{array}{l}\text { Ancef + vancomycin } \\
(\mathrm{n}=1328)\end{array}$ & $\mathrm{p}$ value \\
\hline $\begin{array}{c}\text { Acute kidney } \\
\text { injury (\%) }\end{array}$ & $39(7.8)$ & $168(12.6)$ & 0.002 \\
$\begin{array}{c}\text { Surgical site } \\
\text { infection }(\%)\end{array}$ & $7(1.4)$ & $15(1.1)$ & 0.636 \\
$\begin{array}{c}\text { Percent change in } \\
\text { GFR }\end{array}$ & 47.3 & 44 & 0.186 \\
\hline
\end{tabular}

GFR $=$ glomerular filtration rate.

Table 5. Severity of acute kidney injury based on the Acute Kidney Injury Network (AKIN) staging system

\begin{tabular}{lllr}
\hline $\begin{array}{l}\text { AKIN } \\
\text { stage }\end{array}$ & $\begin{array}{l}\text { Ancef only } \\
(\mathrm{n}=500)\end{array}$ & $\begin{array}{l}\text { Ancef }+ \text { vancomycin } \\
(\mathrm{n}=1328)\end{array}$ & $\mathrm{p}$ value \\
\hline Any stage & $39(7.8)$ & $168(12.6)$ & 0.002 \\
Stage I & $39(7.8)$ & $127(9.6)$ & $<0.001$ \\
Stage II or III & $0(0)$ & $41(3.1)$ & \\
\hline
\end{tabular}

patients returned to within $50 \%$ of baseline kidney function at a mean of 3 days (SD 3.2 days). There was no difference in the time to return to $50 \%$ of baseline renal function between the two groups ( $2 \pm 1.4$ days versus $3 \pm 3.4$ days; mean difference, 0.5 days; $95 \% \mathrm{CI},-0.2$ to 1.2 days; $\mathrm{p}=0.155)$. Two patients in the vancomycin group developed multiorgan system complications requiring dialysis after joint arthroplasty.

Using a multivariate logistic regression to control for potentially confounding variables, we found that dual antibiotic prophylaxis was an independent risk factor for AKI after primary THA/TKA (adjusted OR, 1.82; 95\% CI, 1.252.64; $\mathrm{p}=0.002$ ). ASA classification (adjusted OR, 1.64; 95\% CI, 1.24-2.17; $\mathrm{p}=0.001$ ) and preoperative kidney disease (adjusted OR, 1.81; 95\% CI, 1.30-2.52; p = 0.001) were also independent risk factors. Age, procedure type, EBL, and intraoperative fluid requirements were not significant risk factors for the development of AKI (Table 6).

\section{Discussion}

With potential penalties for readmissions and complications, there is additional incentive to find the optimal antibiotic regimen for prophylaxis before TKA and THA. Although some have proposed the routine addition of vancomycin to the preoperative antibiotic regimen, we and others have shown that the addition of this additional drug did not reduce the incidence of SSI compared with a single drug regimen [33, 36, 39]. Additionally, vancomycin overuse can result in adverse events including nephrotoxicity, ototoxicity, and the development of resistant organisms [2, 13, 40]. Therefore, the purposes of this study are to (1) compare risk of developing AKI between patients receiving prophylactic cefazolin versus without the addition of vancomycin; (2) compare the severity and recovery of AKI in these cohorts; and (3) determine the independent risk factors for AKI in patients undergoing primary hip and knee arthroplasty.

There are several limitations to this study. First, in this series, only one of four surgeons (G-CL) gave cefazolin alone for antibiotic prophylaxis, whereas the remaining three used a dual antibiotic prophylaxis. Although this can result in selection bias, the risk is minimized by the relative large numbers and the lack of differences between the two groups with respect to age, procedure type, preoperative renal status, and ASA classification. Undoubtedly, a prospective randomized study would minimize the risk of bias or confounding variables. Second, we did not take into account the potential contributions of comorbidities such as heart disease or diabetes or medications known to affect renal function. Several drugs such as angiotensin-converting enzyme inhibitors, angiotensin receptor blockers, and nonsteroidal antiinflammatory drugs (NSAIDs) can affect renal function and place patients at risk for renal insult. However, 
Table 6. Univariate and multivariate logistic regression analysis of risk factors for AKI after primary hip and knee arthroplasty

\begin{tabular}{|c|c|c|c|c|c|c|}
\hline \multirow[t]{2}{*}{ Risk factor } & \multicolumn{3}{|c|}{ Univariate analysis } & \multicolumn{3}{|c|}{ Multivariate analysis } \\
\hline & Odds ratio & $95 \%$ confidence interval & $\mathrm{p}$ value & Odds ratio & $95 \%$ confidence interval & $\mathrm{p}$ value \\
\hline Age (years) & 1.01 & $1.00-1.02$ & 0.048 & 1.01 & $0.99-1.02$ & 0.368 \\
\hline Knee arthroplasty & 1.03 & $0.76-1.38$ & 0.871 & 1.23 & $0.84-1.80$ & 0.278 \\
\hline EBL (per $100 \mathrm{~mL}$ ) & 1.03 & $1.00-1.07$ & 0.087 & 1.04 & $0.99-1.09$ & 0.184 \\
\hline Intraoperative fluids (per $100 \mathrm{~mL}$ ) & 1.02 & $1.00-1.03$ & 0.056 & 1.02 & $0.99-1.04$ & 0.149 \\
\hline ASA & 1.75 & $1.33-2.29$ & $<0.001$ & 1.64 & $1.24-2.17$ & 0.001 \\
\hline Dual antibiotic prophylaxis & 1.71 & $1.89-2.47$ & 0.003 & 1.82 & $1.25-2.64$ & 0.002 \\
\hline Preoperative kidney disease & 1.87 & $1.37-2.55$ & $<0.001$ & 1.81 & $1.30-2.52$ & 0.001 \\
\hline
\end{tabular}

$\mathrm{AKI}=$ acute kidney injury; EBL = estimated blood loss; ASA = American Society of Anesthesiologists.

because there were no differences in ASA classification, prevalence of renal disease, and preoperative creatinine or GFR between the two groups, the risk of confounder bias is reduced. Furthermore, during our study period, our pain management protocol did not include NSAID administration, thus minimizing the risk of NSAID-related renal dysfunction. Third, the precise nature of renal injury was not investigated and therefore the definitive cause of AKI cannot be precisely determined. Cefazolin and other beta-lactam antibiotics can cause acute interstitial nephritis, which is not dose- or duration-dependent. This is confirmed by our results because patients receiving cefazolin alone were not immune to developing AKI. However, because the focus of this study was to look at the effect of adding vancomycin on overall renal function, defining the precise nature of renal failure is not critical. Finally, although the routine use of antibiotics in cement for primary THA/THA was not common practice during this study period, we did not document the effect of its use in high-risk patients (ie, immunocompromised patients and prior hardware). However, when antibiotic cement was used, all four surgeons used the same commercially premixed gentamycin cement, which has relatively low concentrations with low risk of systemic toxicity.

Dual antibiotic prophylaxis with vancomycin and cefazolin increased the risk of AKI after primary THA or TKA compared with patients receiving cefazolin alone. A study comparing kidney injury after primary joint arthroplasty with patients receiving flucloxicillin and gentamycin has been shown to increase the rate of renal dysfunction after surgery compared with those receiving cefuroxime alone [35]. Bailey et al. [4] reported on a series of patients undergoing THA or TKA treated with either cefuroxime or flucloxacillin and gentamycin. Their results showed that the two antibiotic groups developed new-onset, transient renal impairment at a higher rate compared with the single antibiotic group (9\% versus $2 \%, \mathrm{p}<0.001$ ) [4]. Additionally, others have reported AKI in patients undergoing treatment of prosthetic joint infections with vancomycin-impregnated cement spacers $[34,38]$. The precise mechanism leading to the cause of transient renal dysfunction is unclear, but potential causes may be included altered pharmacokinetics caused by the combination of antibiotics [34, 38]. Consequently, a risk of routine vancomycin administration in patients undergoing elective primary THA or TKA is the development of postoperative AKI.

Vancomycin and cefazolin was also associated with an increased severity of AKI compared with patients receiving cefazolin alone. Our results are consistent with other previously published reports on this subject $[4,30,38]$ finding an increase in postoperative kidney injury with multiple antibiotic prophylaxis. Furthermore, our data also show the effect that hip and knee arthroplasty can have on patients. Blood loss, transient hypotension, and predisposing host factors (ASA classification and preoperative renal disease) can cause transient renal dysfunction even when vancomycin is not used. The addition of nephrotoxic antibiotics such as vancomycin or gentamycin can stress the patient with borderline kidney functions and precipitate AKI postoperatively [30]. Finally, we previously showed in this series of patients that the addition of vancomycin to the prophylactic antibiotic regimen does not decrease the rate of SSI compared with cefazolin alone [36]. Others also have shown no differences in infection rates using dual antibiotic prophylaxis [33, 39]. Therefore, without clear evidence, the superiority of dual-antibiotic prophylaxis in prevention of infection, the use of dual antibiotics including vancomycin should be carefully considered, weighing the potential benefits of decreasing MRSA infection against the adverse effects of renal toxicity and potential development of resistant organisms. Because vancomycin prophylaxis is recommended in patients who are at high risk for MRSA infection, a preoperative screening and decolonization program for MRSA before elective TKA and THA may play a role in identifying these at-risk patients $[1,10]$.

We also found higher ASA classification and preoperative kidney disease to be independent predictors of AKI postoperatively consistent with prior literature, which reports that medical comorbidities and preoperative kidney 
function can lead to kidney injury after orthopaedic surgery [30]. Jafari et al. [18] found that preoperative kidney disease and medical comorbidities predisposed patients to developing AKI after primary TJA. Kateros and colleagues [20] analyzed 893 various surgical patients and reported that 68 patients $(8 \%)$ and 12 patients $(1 \%)$ developed AKI and chronic kidney disease, respectively. The authors went on to report that in addition to preexisting kidney disease, a history of diabetes mellitus, perioperative dehydration, perioperative shock, administration of NSAIDs, and use of nephrotoxic antibiotics are correlated with the development of postoperatively renal dysfunction.

In summary, a dual antibiotic prophylactic regimen including vancomycin for patients undergoing primary THA or TKA was associated with increased rates of AKI after surgery compared with patients receiving cefazolin alone. The severity of AKI also was higher compared with patients receiving a single antibiotic. Higher ASA and preoperative kidney disease also predispose patients to AKI. Consequently, without clear superiority of infection prevention, routine use of vancomycin should be avoided. Further prospective studies should look at the efficacy of preoperative screening, decolonization, and selective use of vancomycin in high-risk patients on the effect on SSIs after THA or TKA.

Acknowledgments We thank Dr Craig L. Israelite, Dr Jonathan P. Garino, and Dr Charles L. Nelson for contributing patients to this study.

\section{References}

1. American Academy of Orthopaedic Surgeons. Recommendations for the use of intravenous antibiotic prophylaxis in primary total joint arthroplasty. Information Statement 1027. Rosemont, IL, USA: American Academy of Orthopaedic Surgeons; 2011.

2. American Society of Health-System Pharmacists ASHP therapeutic guidelines on antimicrobial prophylaxis in surgery. American Society of Health-System Pharmacists. Am J Health Syst Pharm. 1999;56:1839-1888.

3. Ayliffe GA. Role of the environment of the operative suite in surgical wound infection. Rev Infect Dis. 1991;13(Suppl 10):S800-S804.

4. Bailey O, Torkington MS, Anthony I, Wells J, Blyth M, Jones B. Antibiotic-related acute kidney injury in patients undergoing elective joint replacement. Bone Joint J. 2014;96:395-398.

5. Bozic KJ, Katz P, Cisternas M, Ono L, Ries MD, Showstack J. Hospital resource utilization for primary and revision total hip arthroplasty. J Bone Joint Surg Am. 2005;87:570-576.

6. Bozic KJ, Kurtz SM, Lau E, Ong K, Chiu V, Vail TP, Rubash HE, Berry DJ. The epidemiology of revision total knee arthroplasty in the United States. Clin Orthop Relat Res. 2010;468:45-51.

7. Bozic KJ, Kurtz SM, Lau E, Ong K, Vail TP, Berry DJ. The epidemiology of revision total hip arthroplasty in the United States. J Bone Joint Surg Am. 2009;91:128-133.

8. Bratzler DW, Houck PM; Surgical Infection Prevention Guideline Writers Workgroup. Antimicrobial prophylaxis for surgery: an advisory statement from the National Surgical Infection Prevention Project. Am J Surg. 2005;189:395-404.

9. Carlsson AK, Lidgren L, Lindberg L. Prophylactic antibiotics against early and late deep infections after total hip replacement. Acta Orthop Scand. 1977;48:405.

10. Chen AF, Heyl AE, Xu PZ, Rao N, Klatt BA. Preoperative decolonization effective at reducing staphylococcal colonization in total joint arthroplasty patients. J Arthroplasty. 2013;28(Suppl):18-20.

11. Crawford T, Rodvold KA, Solomkin JS. Vancomycin for surgical prophylaxis? Clin Infect Dis. 2012;54:1474-1479.

12. Dreghorn CR, Hamblen DL. Revision arthroplasty: a high price to pay. BMJ. $1989 ; 296: 648-649$.

13. Elyasi S, Khalili H, Dashti-Khavidaki S, Mohammadpour A. Vancomycin-induced nephrotoxicity: mechanism, incidence, risk factors and special populations. A literature review. Eur J Clin Pharmacol. 2012;68:1243-1255.

14. Fiaccadori E, Maggiore U, Arisi A, Cabassi A, Beghi C, Campodonico R, Gherli T. Outbreak of acute renal failure due to cefodizime-vancomycin association in a heart surgery unit. Intensive Care Med. 2001;27:1819-1822.

15. Haley RW, Culver DH, White JW, Morgan WM, Emori TG. The nationwide nosocomial infection rate: a new need for vital statistics. Am J Epidemiol. 1985;121:159-167.

16. Hill C, Flamant R, Mazas F, Evrard J. Prophylactic cefazolin versus placebo in total hip replacement: report of a multicentre double-blind randomized trial. Lancet. 1981;1:795.

17. Horan TC, Gaynes RP, Martone WJ, Jarvis WR, Emori TG. CDC definitions of nosocomial surgical site infections, 1992: a modification of CDC definitions of surgical wound infections. Infect Control Hosp Epidemiol. 1992;13:606-608.

18. Jafari SM, Huang R, Joshi A, Parvizi J, Hozack WJ. Renal impairment following total joint arthroplasty: who is at risk? $J$ Arthroplasty. 2010;25(Suppl):49-53.

19. Jiranek WA, Hanssen AD, Greenwald AS. Antibiotic-loaded bone cement for infection prophylaxis in total joint replacement. J Bone Joint Surg Am. 2006;88:2487-2500.

20. Kateros K, Doulgerakis C, Galanakos SP, Sakellariou VI, Papadakis SA, Macheras GA. Analysis of kidney dysfunction in orthopaedic patients. BMC Nephrol. 2012;13:101.

21. Kirkland KB, Briggs JP, Trivette SL, Wilkinson WE, Sexton DJ. The impact of surgical site infections in the 1990s: attributable mortality, excess length of hospitalization, and extra costs. Infect Control Hosp Epidemiol. 1999;20:725-730.

22. Kuper M, Rosenstein A. Infection prevention in total knee and total hip arthroplasties. Am J Orthop. 2008;37:E2.

23. Kurtz SM, Ong KL, Lau E, Bozic KJ, Berry D, Parvizi J. Prosthetic joint infection risk after TKA in the Medicare population. Clin Orthop Relat Res. 2010;468:52-56.

24. Levey AS, Coresh J, Greene T, Stevens LA, Zhang YL, Hendriksen S, Kusek JW, Van Lente F; Chronic Kidney Disease Epidemiology Collaboration. Using standardized serum creatinine values in the modification of diet in renal disease study equation for estimating glomerular filtration rate. Ann Intern Med. 2006;145:247-254.

25. Lidwell OM. Air, antibiotics and sepsis in replacement joints. $J$ Hosp Infect. 1988;11(Suppl C):18-40.

26. Lidwell OM, Lowbury EJ, Whyte W, Blowers R, Stanley SJ, Lowe D. Effects of ultraclean air in operating rooms on deep sepsis in the joint after total hip or knee replacement: a randomized study. Br Med J (Clin Res Ed). 1982;285:10-14.

27. Lynch RJ, Englesbe MJ, Sturm L, Bitar A, Budhiraj K, Kolla S, Polyachenko Y, Duck MG, Campbell DA Jr. Measurement of foot traffic in the operating room: implications for infection control. Am J Med Qual. 2009;24:45-52. 
28. Mangram AJ. A brief overview of the 1999 CDC guideline for the prevention of surgical site infection: Centers for Disease Control and Prevention. J Chemother. 2001;13:35-39.

29. Marculescu CE, Osmon DR. Antibiotic prophylaxis in orthopaedic prosthetic surgery. Infect Dis Clinic N Am. 2009;19:931-946.

30. Mavrogenis A, Mitsiokapa EA, Romantini M, Grandinetti V, Coll-Mesa L, Ruggieri P, Papagelopoulos PJ. Acute renal failure in orthopaedic surgery. $J$ Long Term Eff Med Implants. 2011;21:149-158.

31. Mehta R, Kellum J, Shah S, Molitoris B, Ronco C, Warnock D, Levin A, AKINetwork: Acute Kidney Injury Network: report of an initiative to improve outcomes in acute kidney injury. Crit Care. 2007;11:R31.

32. Ong KL, Kurtz SM, Lau E, Bozic KJ, Berry DJ, Parvizi J. Prosthetic joint infection risk after total hip arthroplasty in the Medicare population. J Arthroplasty. 2009;24(Suppl):105.

33. Ponce B, Raines BT, Reed RD, Vick C, Richman J, Hawn M. Surgical site infection after arthroplasty: comparative effectiveness of prophylactic antibiotics: do surgical care improvement project guidelines need to be updated? J Bone Joint Surg Am. 2014;96:970-977.

34. Reed EE, Johnston J, Severing J, Stevenson KB, Deutscher M. Nephrotoxicity risk factors and intravenous vancomycin dosing in the immediate postoperative period following antibiotic-impregnated cement spacer placement. Ann Pharmacother. 2014;48:962-969.
35. Ross AD, Boscainos PJ, Malhas A, Wigderowitz C. Peri-operative renal morbidity secondary to gentamicin and flucloxacillin chemoprophylaxis for hip and knee arthroplasty. Scott Med J. 2013;58:209-212.

36. Sewick A, Makani A, Wu C, O’Donnell J, Baldwin KD, Lee GC. Does dual antibiotic prophylaxis better prevent surgical site infections in total joint arthroplasty? Clin Orthop Relat Res. 2012;470:2702-2707.

37. Smith EB, Wynne R, Joshi A, Liu H, Good RP. Is it time to include vancomycin for routine perioperative antibiotic prophylaxis in total joint arthroplasty patients? $J$ Arthroplasty. 2012;27(Suppl):55-60.

38. Springer BD, Lee GC, Osmon D, Haidukewych GJ, Hanssen AD, Jacofsky DJ. Systemic safety of high-dose antibiotic-loaded cement spacers after resection of an infected total knee arthroplasty. Clin Orthop Relat Res. 2004;427:47-51.

39. Tyllianakis ME, Karageorgos ACh, Marangos MN, Saridis AG, Lambiris EE. Antibiotic prophylaxis in primary hip and knee arthroplasty: comparison between cefuroxime and two specific antistaphylococcal agents. J Arthroplasty. 2010;25:1078-1082.

40. van Hal SJ, Paterson DL, Lodise TP. Systematic review and meta-analysis of vancomycin-induced nephrotoxicity associated with dosing schedules that maintain troughs between 15 and 20 milligrams per liter. Antimicrob Agents Chemother. 2013;57: 734-744. 